\title{
O fim dos riscos?
}

\section{La fin des risques?}

\section{The end of risks?*}

\author{
Claude GILBERT**
}

\section{RESUMO}

No espaço de algumas décadas. profundas mudanças se produziram no tratamento dos perigos suscetíveis de afetar as coletividades humanas. Se desde o fïm do século XIX. assistia-se a uma progressão contínua no sentido de tratar tais perigos como riscos. constata-se atualmente um desgaste deste procedimento que. em múltiplos néveis (técnico. cientílico. econômico. político). permitia admitir certas formas de controlá-los. Tudo parece efetivamente indicar que o trabalho de domesticaçào dos perigos coletivos. empreendido através da generalizaçào da noçào de riseo. tenha chegado a seus limites. $\Lambda$ s razòes desta situação são diversas. É verdade que a própria natureza dos perigos mudou significativamen1e. tornando mais problemática sua abordagem sob a forma de riscos. Mas a dificuldade de tratar os novos perigos no âmbito da idéia de gestão de riseos levou à exploração de outras modalidades de tratamento destes perigos. especialmente por novos atores que se mobilizam ao redor destas questoes que tendem a ser consideradas agora como questoes de sociedade.

Palaveas-chave: limites da abordagem de risco. outras modalidades de tratamento dos perigos. dimensào societária dos perigos

\section{RÉSUMÉ}

En lespace de quelques décennies, de profonds changements sont survenus dans le traitement des dangers susceptibles daffecter les collectivités humaines. Alors que depuis la lin du XIXe siècle on assistait à une progression continue du traitement de ces dangers via leur approche en lant que risques. on constate aujourd hui une érosion de ces procédures qui. sur de multiples plans (technique. scientifique. Économique. politique). permettaient d.envisager certaines formes de maîtrise. Tout semble effectivement se passer comme si le travail de domestication des dangers collectifs entrepris avec la généralisation de la notion de riscue trouvait ses limites. Les raisons de cette situation sont diverses. La nature même des dangers a certes significativement changé. rendant plus problématique leur approche sous forme de

\footnotetext{
* Traduçào de Carmem Lucia Druciak.

** Diretor de Pesquisa do (NRS (Cl:RAT/GiS Riscos Colelivos e Situagios de Crise).
} 
risques. Mais la difficulté de contenir de nouveaux dangers dans le cadre de la gestion des risques a conduit à l'exploration d'autres modalités de traitement des dangers, notamment par de nouveaux acteurs se mobilisant autour de ces questions qui tendent à apparaître comme des questions de société.

Mots-clé: limites de la notion de risque, autres modalités de traitement des dangers. les dangers comme des questions de société

\begin{abstract}
In a lapse of a few decades, deep changes have occurred in the treatment of dangers which may affect human communities. Whereas since the end of the XIXe century there was a continuous progression of the treatment of these dangers through their approach as risks, one notes today an crosion of these procedures which, on multiple plans (technical, scientific, economical, political). made it possible to consider certain forms of control. All seems indeed to occur as if the work of domestication of collective dangers undertaken with the generalization of the concept of risk found its limits. The are several reasons explaining this situation. The nature even of dangers significantly changed. making more problematic their approach in the form of risks. But also, and in a bound way, the difficulty in containing new dangers within the framework of risk management led to exploration of other methods of treatment of dangers. in particular by new actors mobilizations around these questions which tend to become major topics in modern socicties.

Key-words: limits of the concept of risk, others methods of treatment of dangers. treatment of dangers as major topic in modern societies
\end{abstract}

No espaço de algumas décadas, profundas mudanças ocorreram no tratamento dos perigos passíveis de afetar as coletividades humanas. Desde o fim do século XIX, assistia-se a uma progressão contínua no tratamento desses perigos como riscos; hoje constata-se uma defasagem nesses procedimentos, os quais, sobre vários planos (técnico, científico, econômico, político), permitiam vislumbrar certas formas de controle. Tudo parecia indicar que o trabalho de domesticação dos perigos coletivos, empreendidos com a generalização da noção de risco, encontrara seus limites. As razões dessa situação são várias. A própria natureza dos perigos mudou significativamente, tornando mais problemática sua aproximação sob forma de riscos. Do mesmo modo, a dificuldade de conter os novos perigos no quadro de gestão de riscos conduziu à exploração de outras modalidades de tratamento, principalmente através da mobilização de novos atores em torno dessas questões, as quais tendem a apresentar um caráter social.

\section{Dos riscos às ameaças}

Ainda hoje, uma grande parte dos perigos ligados a atividades humanas ou fenômenos naturais pode se transformar em risco graças a métodos experimentados.' De fato, é possível o "estabelecimento do risco",' uma vez que se possa identificar uma ou mais causas, fixar probabilidades de ocorrência, avaliar os danos. Aparentemente simples, essa operação é, na verdade, bastante complexa, visto que solicita conhecimento e mecanismos diversos que permitam selecionar razões em meio ao conjunto de outras possíveis, reter certas relações de causa e efeito, fazer previsões razoáveis graças ao cálculo das probabilidades, introduzir possíveis equivalências entre perdas e compensações (especialmente sob forma de capital) etc. Originária do mundo da segurança e inicialmente marcada por um forte componente arbitrário, a operação de "estabelecimento do risco" tornou-se 
um procedimento corrente e até mesmo um integrante familiar de numerosas contribuições técnicas e científicas, servindo de ponto de apoio às ações e às políticas de prevenção. Em todos os sentidos e em razão de seus inúmeros usos e de sua familiaridade, essa operação se transformou em uma espécie de "caixa-preta", aberta à medida que se multiplicaram os objetos aos quais ela é aplicada. No entanto, a eficácia do "estabelecimento do risco" foi colocada em questão pelo surgimento de novos perigos coletivos que ultrapassaram muito o quadro desse procedimento para nele se inscreverem. Em vários domínios, surgem de fato perigos que, em razão de suas características próprias, parecem se subtrair ao trabalho de redução de incertezas introduzido pela noção de riscos.

Assim, aos riscos industriais clássicos, sempre presentes, são acrescentados "riscos máximos", cuja realidade é ilustrada por diferentes acidentes e catástrofes sobrevindos ao nuclear e à química (Three Mile Island, Chernobyl, Bhopal...). " Transpondo os obstáculos das instalações, tendo às vezes efeitos fora de escala, tanto em razão de sua amplitude como de suas consequiências inéditas no espaço e no tempo, esses riscos raros e devastadores escapam com freqüência a antecipações e domínios.

Evoluções semelhantes são observáveis em todas as atividades ligadas às redes, já que às situações clássicas de transporte, de pessoal e de mercadorias, entre as quais há algumas que podem a todo momento tornarse riscos máximos (como os naufrágios do Amoco Cadiz, do Exxon Valdez, do Erika...), acrescentam-se doravante aquelas atividades ligadas às grandes redes, que asseguram o fornecimento de água e de eletricidade, ou as panes gerais, como tememos com o bug do milênio ou a propagação de alguns vírus. Ainda aqui parece difícil, sendo tantos os perigos que se cruzam, não se podendo medir verdadeiramente o impacto da suspensão ou da interrupção de algumas redes tidas como vitais, fazer com que esses problemas emergentes entrem de fato no quadro da gestão de riscos.

No domínio da saúde pública, constata-se que epidemias clássicas, contaminações alimentares etc. podem igualmente se transformar em "riscos máximos" em razão do rápido e relevante aumento da vulnerabilidade das coletividades humanas. O desenvolvimento da urbanização, a multiplicação dos intercâmbios e, mais ampla- mente, os inúmeros efeitos da globalização são fatores suscetiveis de mudar radicalmente a natureza e o alcance dos perigos sanitários. A esses perigos, porém, acrescentam-se doravante aqueles cuja amplificação é estreitamente determinada pelas atividades humanas (Aids, ESB etc.), assim como os que resultam diretamente dessas atividades, como é o caso de tudo o que se refere à manipulação do elemento vivo (transgênicos, clonagem humana etc.). Se o rápido aumento das possibilidades de difusão apressa o surgimento dos perigos sanitários sob a forma de risco, é obvio que esse enquadramento não é mais eficiente quando se trata de levar em conta perigos que têm muitas características endógenas e/ou ainda dificilmente percebidos enquanto perigos reais (como é, por exemplo, o caso dos transgênicos).

No domínio dito dos "riscos naturais", colocam-se dificuldades cada vez maiores para defini-los em relação ao que seria imputável à natureza, considerando a relevância dos fatores antrópicos. Revela-se especialmente problemático apreender os riscos naturais, uma vez que não se baseiam mais principalmente, ou mesmo exclusivamente, no acaso como força ativa e as vulnerabilidades ligadas aos fatores antrópicos não são reduzidas a simples elementos passivos, a simples "defesas". Por outro lado, o recurso à noção de risco torna-se delicado no momento em que é necessário considerar os fenômenos globais (poluição ambiental, buraco na camada de ozônio, mudança climática...). Os instrumentos necessários para efetuar um "estabelecimento do risco", para tornar gerenciáveis essas questões das coletividades, são particularmente difíceis de elaborar.

No domínio dos perigos passíveis de afetar as coletividades, há, por sua vez, permanência de riscos clássicos, tendência à transformação de uma parte deles em riscos máximos e surgimento de novos perigos com características específicas. Estes têm freqüentemente um caráter endógeno, notado à medida que resultam diretamente das atividades humanas ou aumentam conforme o funcionamento das sociedades contemporâneas. Esses perigos podem afetar interesses vitais dessas coletividades e de seu meio e não conhecem limites espaciais nem temporais definidos. Enfim, eles estão sob o signo de uma grande incerteza, tendo em vista a dificuldade de produzir conhecimento e conceber ações na medida de sua complexidade e amplitude. Isso se dá de forma mais

3 LAGADEC, P. La cirlization dh risque. Paris: Le Seuil, 1981. 
evidente do que com os riscos máximos, pois os novos perigos tendem a situar-se fora do que parece concebível e controlável. Convém, portanto, que sejam considerados mais como ameaças do que como riscos propriamente ditos.

Uma outra característica importante dessas ameaças é que elas suscitam, sobre planos diversos, situações de crise. É um fator de grande instabilidade o fato de que os responsáveis pela economia, as autoridades políticas, os especialistas técnicos e científicos etc. encontram dificuldade em fornecer quadros de análise, propor modos de ação que apreendam e previnam esses novos perigos. Além do fato, que parece evidente, de que há doravante uma grande desproporção entre os meios de que dispõem os atores e os problemas aos quais são confrontados - primeira definição possível da noção de crise -, constata-se que essa incerteza generalizada a respeito dos novos perigos favorece a multiplicação dos atores intervindo em relação a estas questões - outra definição da crise. ${ }^{4}$ Disso resulta um importante desenvolvimento das controvérsias científicas, das disputas de caráter econômico e político etc., que passam a responder a uma parte relevante do debate público. Isso é reforçado ainda mais por grupos e profissões intelectuais, por diversos porta-vozes da "sociedade civil", pela mídia etc., que desenvolvem uma atenção particular para essas questões, caracterizando-as como uma parte dos "problemas sociais", a ponto de não mais se hesitar em definir as sociedades contemporâneas desenvolvidas como, essencialmente, "sociedades do risco". A conseqüência, também bastante inédita, é que as situações importantes de crise se desenvolvem não em relação aos riscos verificados - porém mais exatamente, aos perigos que foram transformados em riscos - ou ainda a riscos realizados, mas em relação a riscos incertos, ameaças que, em razão das características que lhes são atribuídas, apresentam-se como capazes de comprometer o porvir, o próprio futuro da humanidade e seu ambiente. Com esses novos perigos, as possibilidades de crise estão sempre presentes na mesma medida em que eles são propícios a denúncias, alertas, vigilâncias extremas que engatilham os fenômenos de crise. ${ }^{6}$

\section{Além da gestão dos riscos}

O surgimento dos novos perigos tende a modificar radicalmente a gestão do conjunto de perigos que já afetava as coletividades humanas. Entretanto, as situações variam, consideravelmente, segundo os domínios de atividades e os fenômenos envolvidos, de acordo com o que ainda revelam, ampla ou parcialmente, do quadro da gestão dos riscos ou do quanto dele se distanciam. Mas, em todos os casos, são observadas tensões de naturezas diversas, indicando claramente que, de diferentes maneiras, esse modo de tratamento dos perigos parece atingir hoje certos limites.

O domínio dos riscos industriais, em relação àquele pensado pela noção de "riscos máximos", foi o primeiro a ser perpassado por essas tensões. Trata-se de um domínio em que os atores são bem identificados (industriais encarregados das atividades perigosas, autoridades de controle, instâncias de perícia), em que os procedimentos de "estabelecimento do risco" são testados, assim como as ações e políticas de prevenção a eles ligados. Mesmo se, conforme os setores, as modalidades da gestão dos riscos são mais ou menos elaboradas e dão lugar a interações mais ou menos fortes entre os atores imediatamente envolvidos - lembrando as diferenças entre o setor nuclear e o químico -, encontra-se no domínio de riscos "apropriados". A ênfase nos "riscos máximos", no final dos anos 70 , mostrou quais eram os diferentes limites de tal apropriação. Em primeiro lugar, a complexidade crescente dos processos industriais nas empresas de alta tecnologia tende a tornar ilusória a idéia de um verdadeiro e completo controle desses processos, fazendo parecer inevitáveis ou até normais os acidentes que podem ser provocados, ${ }^{8}$ sem que seja possível estabelecer sempre os vínculos entre as inúmeras causas, das quais uma parte é de ordem organi-

\footnotetext{
4 Para tal visualizaçào dos riscos, ver DOBRY, M. Sociologice des crises politiques. Paris: Presses de la Fondation Nationale des Sciences Politiques, 1985: e LAGADEC, P. la gestion des crises. Paris: McGraw-Hill, Paris, 1991. 5 BECK, U. Risk Society. Toward a New modernity. Sage: Londres, 1992

6 CHATEAURAYNAUD, F: TORNY, D. Les somhres précursems. Une sociologie pragmatique de l'alerte et du risque. Paris: Editions de l'EHESS, I999. 7 Considerando a noçào de "proprietarios do risco" ver GUSFIELD, J. R. The ( whure of Puhlic Prohlems. Chicago and London: The University of Chicago Press, 1981 .

8 PERROW, C. Normal Accidents, Living with High-Risk Techmologies. New York, NJ: Basic books, 1999
} 
zacional. Em segundo lugar, a transposição da barreira simbólica, que há muito tempo era o local das instalações por acidentes cujos efeitos não podiam ser contidos em quadros espaço-temporais precisos e que nem sempre podem ser claramente definidos, introduz uma possível e perigosa continuidade entre as instalações industriais e seus ambientes (no sentido amplo do termo). Assim, de duas maneiras, os "riscos máximos" introduziram uma possível desapropriação dos riscos industriais por seus proprietários em potencial, por um lado, revelando a inadequação de uma parte dos conhecimentos provenientes da engenharia para identificar esses riscos e preveni-los e, por outro lado, colocando em evidência a necessidade de mobilizar outros conhecimentos, outras modalidades de ação para apreender os efeitos desses "riscos máximos", especialmente aqueles que permitem uma abordagem em termos de saúde pública.

Mais globalmente e além da perturbação do dispositivo da gestão de riscos, a introdução da noção de "riscos máximos" contribuiu para abrir os sistemas de atores constituídos em torno das atividades industriais. Esta abertura concerne diversos campos, entre os quais, o campo científico (por ocasião de um maior recurso às ciências exatas em sua parte teórica, às ciências humanas e sociais ligadas às questões de saúde pública etc.), o campo administrativo (por ocasião dos cruzamentos de campos de competência e prerrogativas, dependendo do domínio da indústria, do meio, da saúde etc.), o campo político (por ocasião da implicação creditada aos eleitos, principalmente locais, da mobilização de portavozes, de representantes da sociedade civil etc.) etc. Essa abertura dos sistemas de atores é tão grande que a referência aos "riscos máximos" situa a gestão desses ris$\cos$, que não o são propriamente, sempre no limite da gestão da crise. Assim, acidentes simples - como alguns ocorridos no domínio nuclear e freqüentemente ao redor do "coração" do sistema - e até mesmo a evocação de "riscos máximos" em ligação com uma ou outra atividade podem doravante bastar para que se desencadeiem fenômenos de crise, marcados especialmente pelo desenvolvimento de controvérsias científicas, polêmicas públicas e, sobretudo, pela chegada de novos atores, ligados a diversos campos, que introduzem outras concepções de gestão das atividades industriais, e até questionam a existência destas. Até o momento, apesar de sérios alertas, incidentes significativos e alguns acidentes graves, o domínio industrial não foi perturbado pela abertura do sistema de atores. Raras, de fato, foram as novas modalidades de gestão, de acordos etc. que asseguraram uma posição estável aos novos integrantes. As mudanças sobrevindas consideraram, essencialmente, as relações entre os atores científicos, administrativos, políticos, econômicos etc. já "no jogo" ou que poderiam entrar nele. Mas esta situação é suscetível a mudanças rápidas, acidentes particularmente graves, como o de Toulouse, podem servir de catalisador para ampliar o sistema de atores, modificar as relações entre eles, fazendo com que o conjunto de modos de abordagem e de ação corresponda aos perigos ligados a atividades industriais. $E$ a esses acidentes, sempre possíveis, acrescenta-se o fato de que uma parte, daqui em diante importante, dos riscos ligados às atividades industriais se encontra fora das instalações fixas sobre as quais se focalizou a atenção, logo em relação direta com o ambiente. É, por exemplo, o caso do transporte de materiais perigosos, cujos riscos apresentados crescem com a transferência para estas atividades de uma parte importante das funções de estocagem (especialmente na indústria química); da circulação e consumo de produtos vindos da indústria. É também, de certa maneira, o que acontece com a gestão do apoio aos ciclos industriais, com a gestão do lixo, que, como se sabe, é objeto de fortes tensões e polêmicas."

A essas importantes transformações no domínio dos riscos industriais são acrescentadas, ou antes, sobrepostas, ao longo dos anos 80/90, aquelas ligadas à gestão dos problemas de saúde pública, independendo de tais riscos. As tensões neste domínio resultaram do surgimento de uma nova forma de epidemia - a Aids -, que foi o equivalente aos "riscos máximos" no domínio da saúde pública. A particularidade do desenvolvimento dessa epidemia na França é que ela resultou de um vírus até aquele momento desconhecido, mas também, e principalmente, da dificuldade ou incapacidade dos atores designados a priori pelos problemas de saúde pública em se ocupar dele. É verdade que o sistema de saúde francês, voltado majoritariamente para o aspecto curati-

9 BARTHE, Y. La mise e'n politique des déchets muclécires. Thèse (Doctorat) - École Nationale Supérieure des Mines de Paris, Centre de Sociologie de l'Innovation, 2000 
vo, pareceu não ser capaz de conter uma doença que não tinha cura, que alcançava grupos ou indivíduos a princípio considerados marginais (homossexuais, toxicômanos etc.) e, ainda, que necessitava da implantação de meios não-medicinais (seleção de doadores), como foi o caso na Grã-Bretanha e na Suécia, para reduzir a contaminação via transfusão sangüínea." Esse fiasco organizacional contribuiu muito para desapossar os "proprietários" em potencial da saúde pública - a bem dizer, bastante raros e mal-estruturados na França - de uma porção de sua legitimidade e de suas prerrogativas. As associações de vítimas que se formaram contribuíram, por meio da justiça, em questionar o funcionamento do sistema de saúde, a competência do corpo médico, de especialistas científicos e, além disso, a capacidade da administração e das autoridades políticas em assumir suas funções e responsabilidades. " E quando, em uma fase anterior, terapias começaram a ser testadas, associações de doentes introduziram novas regras ao jogo, obrigando tanto os grandes laboratórios como os poderes públicos a modificar seus modos de funcionamento habituais (protocolos compassíveis, por exemplo) e, mais amplamente, a integrar os doentes e seus porta-vozes como atores plenos com quem seria necessário negociar. ${ }^{12}$ Isso ocorreu em tal grau que essas interpelações, e até mesmo denúncias, deram lugar a um importante acompanhamento da mídia, que teve como resultado a ampliação do conhecimento público sobre a questão, mantendo, durante muito tempo, problemas ligados à Aids na agenda pública. Problema específico e próprio do domínio da saúde pública, a questão da Aids acarretou, na origem, numerosas rupturas na abordagem da gestão dos riscos, contribuindo, por sua vez, com a desestabilização desse modo de tratamento dos perigos coletivos. Mesmo se uma parte das disfunções pôde ser atribuida a erros, seguidos de intervenção judicial, evidencia-se no caso da contaminação por transfusão que foram mais as vulnerabilidades próprias do sistema de saúde francês que propiciaram o desenvolvimento da epidemia do que o vírus propriamente dito. Assim, abandona-se o esquema simples, já colocado em questão no quadro dos riscos industriais, que vê o risco como uma força exterior, como figura possível do inimigo. ${ }^{13} \mathrm{Na}$ definição de risco, as vulnerabilidades têm primazia e se vinculam tanto à fraqueza dos detentores em potencial dos problemas de saúde pública na França, quanto aos aspectos cognitivos e lógicos de ação dos atores no centro do sistema de saúde. Por outro lado, e de forma encadeada, a Aids foi também uma experiência em grande escala da gestão não dos riscos, mas de incertezas no contexto de uma sociedade moderna. Aqui, da mesma forma, um grande deslocamento se opera imediatamente quando importantes e duráveis incertezas permanecem ligadas aos perigos. Além disso, e ainda mais do que no caso dos "riscos máximos" do domínio industrial, confirmou-se que não havia mais distinção verdadeira entre a gestão dos problemas ligados à Aids e a gestão de situação de crise. O fenômeno de crise nos seus múltiplos aspectos se tornou comum e a questão da Aids foi efetivamente partilhada por numerosos atores, dependentes de vários campos. Por intermédio da Aids, os problemas de saúde pública aparecem, assim, mais como riscos endógenos que como riscos exógenos, com incertezas freqüentemente difíceis de reduzir. Também revelam-se mais como fontes potenciais de crise, provocando, sem cessar, a abertura e a reconfiguração de sistemas de atores, a concorrência entre várias abordagens das questões a resolver etc., do que como riscos suscetíveis de ser enquadrados.

As rupturas mais importantes em matéria de gestão de risco, em parte anunciadas pelos "riscos máximos" do domínio industrial e os riscos de saúde pública, como Aids, foram ainda mais nítidas nos anos 90 , com o surgimento de perigos ao mesmo tempo potencialmente importantes e marcados por grandes incertezas. Podemse incluir nesta categoria os perigos ligados aos transgênicos, ao l:SB ("doença da vaca louca"), às poluições ambientais, ao uso de alguns produtos provenientes de novas tecnologias (telefones celulares, por exemplo) etc. A princípio muito diversos, esses perigos têm em comum causas que não podem ser verdadeiramente definidas, considerando que são importantes e duráveis as controvérsias científicas que as concernem; eles escapam amplamente às possibilidades de cálculo e à no-

I0 SETBON, M. Pom oms comme sida. Paris: Le Seuil, 1993.

11 HERMITTE, M. le samg e't le dreit. Essai sur la transfusion sanguine. Paris: Le Seuil, 1996.

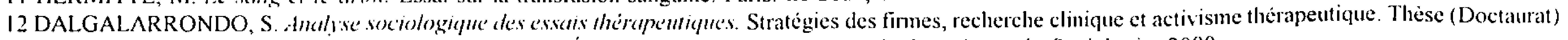

- Fondation Nationale des Sciences Politiques, Institut d’Études Politiques de Paris, Cycle Stıpérieure de Sociologie, 2000.

13GILBERT, C. Le ponroir en simation extreme. Catastrophes et Politiques. Paris: L'Harmattan, 1992. 
ção de ocorrência, tendendo a perder todo sentido. Também não são apreendidos através de seus efeitos ao mesmo tempo dificilmente perceptíveis, mal relacionados às causas, e suscetíveis de surgir tardiamente e até mesmo, em alguns casos, de se transmitir de uma geração a outra, etc. Com tais perigos, a operação de "estabelecimento do risco" se mostra impossível ou ilusória, pois a incerteza de uma possível transformação de um perigo em risco aparece a todo momento. Trata-se, desse modo, realmente de ameaças, dificilmente percebidas e que podem estar na origem de inúmeros e diferentes fenômenos de crise. Esses novos perigos são efetivamente propícios ao desenvolvimento de situações de crise, pois são objeto de indagações de caráter fundamental (papel da ciência, relação homem-natureza, condições de reprodução da humanidade, preservação do patrimônio das gerações futuras etc.) e colocam sempre em jogo importantes interesses econômicos (isenção no caso de mercados emergentes ou estabelecidos, possibilidades de posicionamentos firmes etc.), introduzem grandes "riscos" de desestabilização das autoridades administrativas, políticas, científicas, regularmente tomadas por lógicas contraditórias (desenvolvimento da economia, manutenção das capacidades de inovação, de um lado, tomada de responsabilidade em matéria de segurança coletiva, respeito a princípios éticos etc., de outro). Conseqüentemente, um deslocamento muito importante tende a se operar na maneira de tratar esses perigos, com a introdução de novas concepções, como o "princípio de precaução", que visa a tornar possível o engajamento de ações em um mundo incerto; ${ }^{1+}$ como a implantação de novas formas de perícia e de consulta, visando tanto a modificar o papel dos cientistas, seu modo de intervenção, as modalidades de produção do conhecimento como a dar um novo lugar aos "cidadãos", aos representantes da sociedade civil, aos "profanos". Com os novos perigos que envolvem a atenção pública a ponto de se tornarem objetos recorrentes de debate, afasta-se completamente do quadro da gestão de riscos para aproximar-se da exploração de uma democracia técnica. ${ }^{16}$ Deixa-se então a sociedade do risco, com esses sistemas de atores especializados a cargo da transformação de riscos em perigos, para se ingressar na sociedade das ameaças, em que, pela incapacidade de reduzir as incertezas ligadas aos perigos, essas ameaças são debatidas em quadros ampliados, não apenas graças a uma renovação dos atores e sistemas destes, mas também a uma mudança bastante radical na maneira de conceber a produção de conhecimentos e o engajamento de ações.

É compreensível que, levando em conta a novidade das questões colocadas, a atenção se fixe atualmente sobre as novas ameaças, que escapam aos procedimentos clássicos de "estabelecimento do risco". Também é esperada uma busca prioritária por modalidades específicas que possam ser colocadas em andamento para gerenciar essas ameaças, responsáveis efetivamente pela ultrapassagem de muitas fronteiras, que misturam estreitamente perícia e consulta e levam à concepção de novas formas de co-produção de saberes em uma democracia técnica renovada. Mas essas novas ameaças não podem, sem inconvenientes, mobilizar toda a atenção. Nas sociedades contemporâneas desenvolvidas, há, com efeito, uma coexistência de numerosas atividades e perigosos fenômenos que correspondem a "idades" ou "gerações diferentes". Uma parte importante dessas atividades e fenômenos ainda depende muito dos procedimentos de "estabelecimento do risco". A incerteza que lhes é atribuída pode ser reduzida suficientemente em todo caso para que eles entrem no quadro de gestões e até de rotinas. Isso não exclui as vigilâncias, organizadas especialmente a partir de um reforço das competências e meios do conjunto dos principais atores da gestão desses riscos (principalmente no que concerne às autoridades de controle e às agências de perícia); a partir de uma maior cooperação entre esses atores no que diz respeito à separação de seus papéis; a partir também de uma integração efetiva na gestão dos riscos de atores "interessados" de diversas formas em participar e/ou assumindo funções de porta-vozes de grupos, de profissões, de diversos públicos etc. A maior parte dos perigos suscetíveis de afetar as coletividades pode então ser gerada sobre este modo, que permite assegurar os controles e domínios suficientes. Por outro lado, uma outra parte dos perigos que, hoje, parece escapar ao procedimento de "estabelecimento do risco", logo à gestão que ela autoriza, poderia ser novamente apreendida

14 KOURILSKY, P.: VINEY, G. Le principe de précumion. Paris: Odile lacob-La Documentation, 2000.

15 RABEHARISOA, V: CALLON, M. Le Pom doir des malades. L'Association française contre les myopathies et la recherche. Paris: Les Presses de l'Ecole des

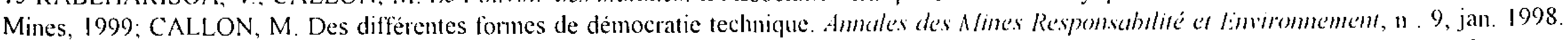

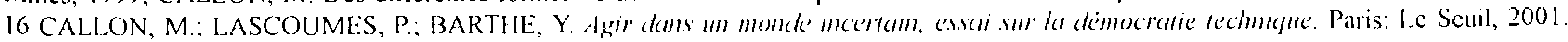


graças à renovação desse procedimento. A integração, por exemplo, do caráter endógeno dos riscos por meio da consideração dos fatores organizacionais, da confiabilidade organizacional, ${ }^{17}$ poderia ampliar muito a eficácia do "estabelecimento do risco". O mesmo ocorre com as novas formas de vigilância - que, tanto sobre $o$ plano técnico, humano, quanto organizacional, tendem a se instaurar nas atividades de alta tecnologia para descobrir os causadores de incidentes, de acidentes e até mesmo de catástrofes, às vezes em ligação com medidas de qualidade, às vezes não, - contribuem igualmente para aumentar a eficácia de procedimentos mais dinâmicos de gestão de riscos, mais voltados para o futuro. De maneira mais geral, a reflexão que se faz hoje sobre o caráter normalmente imperfeito dos sistemas sociotecnológicos, que colocam em andamento atividades perigosas, sobre o domínio desses sistemas e portanto dos riscos adquiridos pela permanente correção de disfunções tanto inevitáveis quanto necessárias, poderia permitir a introdução de concepções radicalmente novas na gestão dos riscos, permanecendo em um tal ambiente. ${ }^{18}$ Isso poderia levar a uma aproximação e não a um distanciamento de uma parte das atividades e fenômenos perigosos.

\section{REFERENCIAS}

AMALBERTI, R.; GILBERT, C. De la gestion des risques technologiques à la gestion des danger's collectifs. Universalia 2001. Paris: Encyclopaedia Universalis France. 2001. p. 9096.

EWALD, F. L'État providence. Paris : Grasset, 1986. p. 20.

AMALBERTI, R.; FUCHS, C.; GILBERT, C. (Dir.). Risques, erreurs et défaillances, approche interdisciplinaire. Atas da primeira seção do seminário Le risque de défaillance et son contrôle par les individus et les organisations dans les activités à hauts risques, CNRS - Ministério da Pesquisa, Grenoble, Publicações da MSH-Alpes, 2001.
A questão que se coloca hoje não é apenas aquela do "fim dos riscos", do início da era das ameaças, mas aquela da possibilidade de estender e renovar o procedimento de "dispor como risco" para limitar somente às ameaças, quer dizer, ao que escapa efetivamente a este procedimento, a experimentação de novas formas de tratamento dos perigos. No entanto, as respostas a esta pergunta não são simples. É, de fato, levantado o problema da consideração dos perigos, da sua hierarquização e, do mesmo modo, dos interesses que suscitam ou não em uma dada conjuntura. Ora, é necessário constatar que são os perigos que se aparentam a novas ameaças que estão no centro dos debates e das reflexões atuais e que, essencialmente, é através deles que são pensados, hoje, os perigos coletivos em todas as conseqüências que podem causar, em termos de apagamento, de ocultação tanto de perigos podendo simplesmente tomar a forma de riscos como de perigos no estatuto mais intermediário, cuja incerteza poderia ser reduzida por uma renovação dos procedimentos de mise en risque. É provável então que, hoje, as condições prévias a qualquer reflexão sobre os perigos, os riscos e as ameaças sejam o engajamento de uma interrogação crítica sobre esse aspecto.

BARTIIE. Y. La mise en politique des déchets nuclëaires. Thèse (Doctorat) - École Nationale Supéricure des mines de Paris. Centre de Sociologie de l'Innovation. 2000.

BECK. U. Risk Society. Toward a New modernity: Sage: Londres, 1992.

BOURRIER, M. (Dir.). Organiser la Fiabilité. Paris: L'Harmattan. 2001 .

CALLON. M. Des différentes formes de démocratie technique. Annales des Mines Responsabilité et Environnement, n. 9.jan. 1998. 
CALLON, M.: LASCOUMES. P.: BARTHE, Y. Agir dans un monde incertain, essai sur la démocratie technique. Paris: Le Seuil. 2001.

CHATEAURAYNAUD, F.: TORNY, D. Les sombres précurseurs. Une sociologie pragmatique de l'alerte et du risque. Paris: Editions de l'EHESS, 1999.

DALGALARRONDO. S. Analyse sociologique des essais thérapeutiques. Stratégies des firmes. recherche clinique et activisme thérapeutique. Thèse (Doctaurat) - Fondation Nationale des Sciences Politiques. Institut d'Études Politiques de Paris, Cycle Supérieure de Sociologie. 2000.

DOBRY. M. Sociologie des crises politiques. Paris: Presses de la Fondation Nationale des Sciences Politiques, 1985.

EWALD. F. L'État providence. Paris: Grasset. 1986. p. 20.

GILBERT. C. Le pouvoir en situation extrême. Catastrophes et Politiques. Paris: LiHarmattan. 1992.
GUSFIELD. J. R. The Culture of Public Problems. Chicago and London: The University of Chicago Press. 1981.

HERMITTE, M. Le sang et le droit. Essai sur la transfusion sanguine. Paris: Le Seuil, 1996.

KOURILSKY, P.: VINEY, G. Le principe de précaution. Paris: Odile Jacob-La Documentation. 2000

LAGADEC. P. La civilization du risque. Paris: Le Seuil. 1981.

LAGADEC. P. La gestion des crises. Paris: McGraw-llill. 1991.

PERROW, C. Normal Accidents, Living with High-Risk Technologies. New York, NJ: Basic books, 1999.

RABEHARISOA. V.: CALLON. M. Le Pouvoir des malades. $L$ 'Association française contre les myopathies et la recherche. Paris: Les Presses de l'ícole des Mines. 1999.

SETBON. M. Pouvoirs contre sida. Paris: Le Seuil, 1993. 